\title{
Understanding the relationship between family communication and the development of weight stigma
}

\section{BACKGROUND}

This study examined the relationship between family communication and weight stigma. The Family Communication Patterns Theory was used as a framework to explain the relationships between two dimensions of family communication (i.e., conversation orientation and conformity orientation) and antifat attitudes (i.e., physical unattractiveness and weight blame).

\section{PARTICIPANTS AND PROCEDURE}

A total of 585 college-aged participants completed an online questionnaire. We used the following instruments: body mass index (BMI), Antifat Attitudes Scale (AFAT), Revised Family Communication Patterns Scale (RFCP).

\section{RESULTS}

Significant relationships were found between the two dimensions of family communication and antifat attitudes. Conversation orientation was negatively associated with antifat attitudes and conformity orientation was positive- ly associated with antifat attitudes. In addition, pluralistic families were less likely to stigmatize the overweight and obese by demonstrating less discrimination with physical attraction and personal weight blame.

\section{CONCLUSIONS}

These findings highlight the important association between family communication and antifat attitudes. Families that endorse a pluralistic family type (i.e., high conversation orientation and low conformity orientation) appear to engage in the least amount of discrimination with regard to weight stigma. These families are not only less discriminating of others, they perhaps bring about more awareness and information to family members as compared to other family types.

\section{KEY WORDS}

family communication patterns; obesity; weight stigma; antifat attitudes 


\section{BACKGROUND}

Obesity stigma is one of the most harmful and lasting forms of stigma (Andreyeva, Puhl, \& Brownell, 2008; Latner \& Stunkard, 2003; Sutin, Stephan, Carretta, \& Terracciano, 2015), leading to discrimination in areas such as employment, education, and healthcare (Puhl \& Heuer, 2009). Existing obesity stigma research has primarily focused on the effects of stigma (see Puhl \& Heuer, 2009) and psychological origins of stigma (see
Mary Beth Asbury, Alesia Woszidlo Puhl \& Brownell, 2003). However, few studies have focused on the association between weight stigma and the role of the family in children's attitudes toward weight.

To examine the role of the family in children's weight socialization, we chose to focus on family communication, for research supports the notion that family communication socializes individuals regarding societal attitudes and behaviors (Fitzpatrick \& Ritchie, 1993; Koerner \& Fitzpatrick, 2002a, b). In this study, we expand on the current family communication research by examining the role of family communication patterns and their relationship to weight stigma. Specifically, we examine the association between conversation and conformity orientations of family communication and antifat attitudes.

\section{STIGMA}

The present study examines stigma in terms of Goffman's (1963) conceptualization of the term stigma, which is viewed as any characteristic that is deeply shameful to its possessor and distinguished between three types of stigma: abominations of the body, tribal stigma, and blemishes to individual character. Abominations of the body refer to physical deformities; tribal stigmas refer to stigmas associated with race, religion, and social class; and blemishes to individual character refer to mental illness and addiction. These stigmatizations lead to a spoiled identity, which refers to an identity that prevents one from complete social acceptance. The consequences for not being normal are often severe, and as a result, the stigmatized learn to adapt their behavior and self-presentation to fit society's standards. All stigmatizing messages provide the necessary cues to distinguish and categorize people as separate social entities, while also making connections between this group and certain undesirable physical or social characteristics (Smith, 2007). While there are numerous reasons why a person or persons may be stigmatized, the present study focuses weight stigma.

\section{WEIGHT STIGMA}

The form of stigma associated with the obese is unique in terms of physical conditions, for obese people are often perceived to have brought their conditions on themselves (Crandall, 1994; Hansson \& Rasmussen, 2014; Musher-Eizenman, Holub, Miller, Goldstein, \& Edwards-Leeper, 2004). The stigma associated with obesity is different from stigma associated with other physical conditions, such as certain forms of cancer (e.g., breast cancer and prostate cancer). These maladies are attributed to genetics or "bad luck" rather than personal responsibility (Crandall \& Moriarty, 1995).

When individuals stigmatize other targets (e.g., sexual orientation, race, gender), they are often shamed and corrected, but obesity stigma is one of the still considered an acceptable stigma (Puhl \& Brownell, $2001,2003)$ due to the perception that obesity is controlled by the individual (Ebneter, Latner, \& O'Brien, 2011; Katz, 2014; Tomiyama et al., 2015). This has led to discrimination in areas such as education, employment, and healthcare (Dhurandhar, 2013; Puhl \& Heuer, 2009; Latner, O’Brien, Durso, Brinkman, \& MacDonald, 2008). While other weight groups, such as those who are underweight, also experience weight stigma, the stigma associated with the overweight and obese is more severe (Andreyeva et al., 2008). Research examining perceptions of those with eating disorders demonstrates that although eating disorders are generally perceived to be negative, participants consistently attribute benefits to having an eating disorder and admiration for those who suffer (Anderson, 2013; Mond, Robertson-Smith, \& Vetere, 2006; Roehrig \& McLean, 2010) because being thin and/or losing weight is viewed as valuable in western society. Obesity, on the other hand, is considered as immoral and disgusting (O’Brien et al., 2013; Townsend, 2009).

Research (e.g., Puhl \& Heuer, 2009) has shown that there are many sources of weight stigma, including family. For example, the frequency of weight stigma messages, as reported by both men and women, is higher for family members than employers or supervisors, mental health professionals, nurses, or general community members (Puhl \& Brownell, 2006; Puhl \& Heuer, 2009; Puhl, Moss-Racusin, Schwartz, \& Brownell, 2008). Puhl et al. (2008) found that most overweight individuals have experienced some form of teasing or name-calling from their parents and/or siblings. Yet, there has been a lack of research regarding how these stigmatizing messages develop in the family.

The current study examines the associations between family communication patterns and a specific form of weight stigma, antifat attitudes. Family members who communicate stigmatizing messages about weight could be contributing the development and perpetuation of general weight stigma.

\section{FAMILY COMMUNICATION PATTERNS THEORY}

As the aforementioned literature notes, obesity stigma is prevalent, yet the question that remains 
is where are these group norms being learned, specifically in terms of obesity stigma? To answer this question, we turn to family communication patterns theory. Past and current research supports the notion that family communication has an influence on one's behaviors within and outside the family unit, influencing children's beliefs, values, how they perceive their social environment, and how they create and maintain interpersonal relationships (Fitzpatrick \& Ritchie, 1993; Koerner \& Fitzpatrick, 2002a, b; Koerner \& Schrodt, 2014).

There are two fundamental dimensions of Family Communication Patterns (FCP): Conversation orientation and conformity orientation (Fitzpatrick \& Ritchie, 1994; Ritchie \& Fitzpatrick, 1990). Conversation orientation is "defined as the degree to which families create a climate in which all family members are encouraged to participate in unrestrained interaction about a wide variety of topics" (Koerner \& Fitzpatrick, 2006, p. 54). Families high in conversation orientation emphasize open communication and all family members are encouraged to express ideas (Koerner \& Fitzpatrick, 2002b). Conformity orientation "refers to the degree to which family communication stresses a climate of homogeneity of attitudes, values, and beliefs" (Koerner \& Fitzpatrick, 2006, p. 55). Families high in conformity orientation tend to have interactions that stress obedience to parents, adherence to family beliefs and attitudes, and conflict avoidance (Koerner \& Fitzpatrick, 2002b).

Based on these dimensions, families are categorized into one of four types: consensual, pluralisitic, protective, and laissez-faire. Consensual families are high in conversation and conformity orientations, and parents in these families are interested in interacting and spending time with their children (Fitzpatrick \& Ritchie, 1994; Koerner \& Fitzpatrick, 2002b). Pluralistic families are high in conversation orientation but are low in conformity orientation, valuing open discussion (Fitzpatrick \& Ritchie, 1994; Koerner \& Fitzpatrick, 2002b). Protective families are low in conversation orientation but high in conformity orientation (Fitzpatrick \& Ritchie, 1994; Koerner $\&$ Fitzpatrick, 2002b). These families have little open communication, and obedience to parents is emphasized. Finally, laissez-faire families are low in conversation orientation and low in conformity orientation, and parent-child interaction is limited (Fitzpatrick \& Ritchie, 1994; Koerner \& Fitzpatrick, 2002b).

Research is extensive regarding FCP and cognitive, affective, and behavioral processes (Schrodt \& Ledbetter, 2007; Schrodt, Witt, \& Messersmith, 2008; Segrin, 2006). Family Communication Patterns has been found to be associated with anxiety and depression (i.e., conformity orientation was negatively associated with depression; Koerner \& Fitzpatrick, 1997), communication apprehension (i.e., conversation orientation was negatively associated with com- munication apprehension; Elwood \& Schrader, 1998), perceived stress (i.e., families with high conversation orientation have children who report less perceived stress; Koerner \& Fitzpatrick, 2002b; Schrodt, Ledbetter, \& Ohrt, 2007). To our knowledge, one area of literature that has yet to be researched is family communication patterns and weight stigma. Because the family environment is often thought of as a major foundation for children's attitudes, beliefs, and behaviors, it is possible that family communication aids in the development of attitudes about physical weight.

Weight and family communication. The role of family communication and weight has been examined extensively regarding eating disorders (i.e., anorexia nervosa and bulimia nervosa) and body image. Overall, research (e.g., Joiner, Heatherton, Rudd, \& Schmidt, 1997; Levine, 1996; Wonderlich, 1992) has shown a correlation between women with eating disorders and family functioning. Family environments where weight and eating patterns are frequently talked about are associated with higher instances of eating disorders in children (Kluck, 2010). Research (e.g., Al Sabbah et al., 2009; Coomber \& King, 2008; Kluck, 2010) has also shown the effects of dyadic family relationships (e.g., mother-daughter, sister-brother) on eating patterns and body image. Mothers can influence their daughters' body image through their own attitudes and eating behaviors (Cooley, Toray, Wang, \& Valdez, 2008), and sibling relationships can affect eating attitudes by promoting a culture of thinness (Coomber \& King, 2008). In addition, family communication, specifically the expression of emotion, is associated with thoughts of disordered eating (Arroyo \& Segrin, 2013; Segrin \& Flora, 2011). Berge, Wall, Larson, Loth, and Nuemark-Sztainer (2013) found that family functioning was related to adolescents' health behaviors, such as eating fruits and vegetables, physical activity level, and weight. Moreover, family communication patterns directly affect health attitudes (Baiocchi-Wagner \& Talley, 2013) and body dissatisfaction (Taniguchi \& Aune, 2013). These findings indicate that family structure and type have an influence on children's own body image and eating behaviors. However, there is still a question regarding how these family communication behaviors are associated with how children view others in terms of body weight.

\section{THE CURRENT STUDY}

The current study examines the role of family communication and attitudes toward the overweight and obese. Family communication is related to health outcomes in children and adolescents (Arroyo \& Segrin, 2013; Baiocchi-Wagner \& Talley, 2013; Berge et al., 2013), but there is no research in terms of how
Family communication patterns and weight stigma 
family communication affects children's perceptions of others' health.

Family Communication Patterns posits that families who create a climate in which family members are encouraged to communicate about a variety of topics are more likely to have frequent exchanges of values and opinions that help educate and socialize children (Koerner \& Fitzpatrick, 2006; Koerner $\&$ Schrodt, 2014). Further, research has shown that people who employ open communication about physical and mental stigmas tend to have more positive and accepting attitudes toward the stigmas and persons with the stigmas (Hinshaw, 2007). Although most of this research has been examined in terms of racial prejudice, the overall consistent finding has shown that talking about the condition makes individuals more sympathetic to those who are outside of the group norm (Hinshaw \& Stier, 2007).

Family Communication Patterns also postulates that families who stress conformity are more likely be traditional and hierarchical (Koerner \& Fitzpatrick, 2006). High conformity has been associated with less personal growth of family members, more parental control over children's decisions, less empathy, and less perspective taking (Koerner \& Fitzpatrick, 2002b). This suggests that people who grow up in families high in conformity would be less accepting of stigmas because they would be unable to see beyond the characteristics (e.g., size of the person, space that a person takes up, etc.) that indicate someone is overweight or obese.

Our first hypothesis examines the dimensions of FCP and attitudes toward overweight and obese people. As noted by previous research (e.g., Puhl \& Brownell, 2006; Puhl \& Heuer, 2009; Puhl et al., 2008), family members are the most common and frequently cited sources of stigma. Therefore, it is plausible that families who perpetuate stigmas are also more closed-minded and conforming regarding messages about weight. Conversely, families wherein open communication is encouraged are perhaps less stigmatizing because they are able to openly discuss issues and potentially challenge the negative perceptions attached to overweight and obese people. Thus, H1a posits that individuals from families who are high in conversation orientation will be less likely to deem a person unattractive because of his/her weight while those from families high in conformity orientation will be more likely to view an overweight person as unattractive. $\mathrm{H} 1 \mathrm{~b}$ predicts that individuals from families who are high in conversation orientation will be less likely to believe the overweight or obese person is to blame when it comes to his/her weight problem, while individuals from families who are high in conformity orientation are more likely to blame an overweight person for his/her weight problem. Again, the rationale for this hypothesis stems from research that suggests people who openly and positively communicate about stigmas will potentially be more accepting of the stigma (e.g., Hinshaw, 2007; Hinshaw \& Stier, 2007) and that those who are higher in conformity may be less empathic toward others and less open to multiple perspectives (Koerner \& Fitzpatrick, 2002b).

Because the effects of FCP's two dimensions (i.e., conversation and conformity) are often dependent on one another, it is important to examine any interaction effects that these dimensions have on weight stigma. Koerner and Fitzpatrick (2002b) suggest that in order to predict the influence of family communication patterns on family outcomes, it is best to test both dimensions simultaneously. Therefore, our second hypothesis predicts that pluralistic families, who are high in conversation orientation and low in conformity orientation, will have the least discrimination toward overweight or obese individuals. We believe this combination of the two dimensions will allow for the least biased, negative exchange of information about weight stigma.

\section{PARTICIPANTS AND PROCEDURE}

College students in an introductory communication course at a large Midwestern university were administered an on-line questionnaire designed to measure family communication patterns, fat attitudes, body mass index (BMI), and parents' weights. A total of 592 participants completed the on-line questionnaire. However, 7 questionnaires were discarded because these participants completed less than $10 \%$ of questionnaire $(n=4)$ or their age (i.e., above 45$)$ deemed them an outlier $(n=3)$. Thus, the final sample included 585 participants (448 women and 129 men) with a mean age of $20.64(S D=2.07)$. Collectively, this sample was $79 \%$ White, $5 \%$ Asian/Pacific Islander, 4\% Hispanic/Latino(a), 3\% African American/Black, $0.2 \%$ Native American and 3\% "other".

With regard to BMI, participants self-reported their height and weight. This information was used to calculate their BMI (BMI = (weight in pounds * 703) / height in inches ${ }^{2}$. While scholars have noted that there are problems with using BMI as a means of measuring health in terms of weight and that other measures, such as body fat percentage and weight circumference, are more accurate, most medical professionals still use BMI as a means for diagnosing and treating obesity (Centers for Disease Control and Prevention, 2015). In addition, although some participants will fabricate ideal height and weight measurement on survey instruments, research has shown that effects are minute (Gorber, Tremblay, Moher, \& Gorber, 2007).

Participants were then divided into four groups based on their BMI - underweight (i.e., BMI below 18.5), normal weight (i.e., BMI between 18.5-24.9), 
overweight (i.e., BMI between 25-29.9), and obese (i.e., BMI 30 and above) (Centers for Disease Control and Prevention, 2015). Of the participants who reported their information, $5 \%$ reported a BMI that registered at underweight $(n=31), 68 \%$ reported a BMI that registered at normal weight $(n=400), 14 \%$ reported a BMI that registered at overweight $(n=84)$, and $6 \%$ reported a BMI that registered at obese $(n=35)$.

Participants also reported the perception of his/ her parents' weight in terms of BMI categories (i.e., severely underweight, underweight, normal weight, overweight, obese, and morbidly obese). Each participant reported their mother's weight as severely underweight (1\%), underweight (8\%), normal weight (67\%), overweight $(22 \%)$, or obese (2\%). Additionally, participants reported their father's weight as severely underweight $(0.3 \%)$, underweight $(4 \%)$, normal weight $(70 \%)$, overweight $(24 \%)$, obese $(1 \%)$, or morbidly obese $(0.3 \%)$. While we note that these descriptions may not be accurate, we were more interested in participants' perceptions of their parents' weight rather than accuracy.

\section{MEASUREMENTS}

Antifat Attitudes Test. Antifat attitudes were assessed with two subscales from the Antifat Attitudes Test (AFAT; Lewis, Cash, Jacobi, \& Bubb-Lewis, 1997). First, participants completed 10 items that assessed the physical/romantic unattractiveness of "fat" people. Sample items include, "I can't believe someone of average weight would marry a fat person", "It's disgusting to see fat people eating", or "Fat people are physically unattractive". Higher scores on this scale reflect negative attitudes about "fat" people's physical and interpersonal attractiveness such that they are unacceptable as romantic partners. Cronbach's $\alpha$ for this scale was .82. Next, participants completed the second subscale, which was comprised of 9 items that assessed weight control/blame. Sample items include, "There's no excuse for being fat", "If fat people really wanted to lose weight, they could", or "Most fat people will latch onto almost any excuse for being fat". Higher scores on this scale reflect more personal blame for weight problems. All items were scored on a 5-point Likert scale, with 1 = strongly disagree to 5 = strongly agree. The scale achieved a reliability of .82 .

Family Communication Patterns. The Revised Family Communication Patterns Scale (RFCP) was used to assess perceptions of family communication along two dimensions (i.e., conversation orientation and conformity orientation) (Ritchie \& Fitzpatrick, 1990). Fifteen items were used to examine conversation orientation, which refers to the degree to which family communication creates a climate that welcomes unrestrained interactions and does not place limitations on topics discussed. Sample items include, "I usually tell my parents what I'm thinking about things", or "My parents and I often have long, relaxed conversations about nothing in particular". High scores on this scale reflect families that "freely, frequently, and spontaneously interact with one another" (Koerner \& Fitzpatrick, 2006, p. 54). Cronbach's $\alpha$ for this scale was .92. Participants also completed 11 items that measured conformity orientation, or the degree to which family communication emphasizes homogenous attitudes, values and beliefs. Sample items include, "When anything really important is involved, my parents expect me to obey without question", or "My parents sometimes become irritated with my views if they are different from theirs". High scores on this scale reflect families that stress the uniformity of beliefs and attitudes and promote harmonious interactions. All items on the RFCP were scored on a 5-point Likert scale, with 1 = strongly disagree to 5 = strongly agree. Cronbach's $\alpha$ for this scale was .83 .

In addition to these scales, participants completed a number of demographic items, such as sex, age, race/ethnicity, weight and height.

\section{RESULTS}

Means, standard deviations, and zero order correlations for all variables in this investigation can be found in Table 1. Hypothesis 1 examined the relationship between the two dimensions of family communication (i.e., conversation and conformity) and antifat attitudes (i.e., physical unattractiveness and weight blame). H1a predicted that individuals from families who are high in conversation orientation would be less likely to discriminate the attractiveness of a person because of his/her weight while individuals from families who are high in conformity orientation would more likely to find overweight people as unattractive. $\mathrm{H} 1 \mathrm{~b}$ predicted that individuals from families who are high in conversation orientation would be less likely to place personal blame on an overweight or obese individual while individuals from families who are high in conformity orientation would be more likely to place personal blame on overweight people. Two hierarchical regression analyses were conducted. For each regression analysis, BMI (for participants, mothers, and fathers) and sex were entered in each model as step 1 . Step 2 of the model contained conversation orientation and conformity orientation. All regression coefficients are reported in standardized form.

The first regression model was tested with physical unattractiveness as the dependent variable. Step 1 of the model (BMI and sex) contributed significantly to the regression model, $F(4,480)=6.22$, $p<.001$, and accounted for $5 \%$ of the variance in physical unattractiveness. Adding the two dimensions explained an additional $3 \%$ of variation in
Family communication patterns and weight stigma 
Table 1

Means, standard deviations, and zero order correlations of all test variables

\begin{tabular}{|c|c|c|c|c|c|c|c|}
\hline & 1 & 2 & 3 & 4 & 5 & 6 & 7 \\
\hline 1. Conversation orientation & - & & & & & & \\
\hline 2. Conformity orientation & $-.27^{* * *}$ & & & & & & \\
\hline 3. Weight unattractiveness & $-.15^{* *}$ & $.13^{* *}$ & & & & & \\
\hline 4. Weight blame & $-.10^{*}$ & $.14^{* *}$ & $.69^{* * *}$ & & & & \\
\hline 5. Mother's weight & -.06 & -.03 & $-.12^{* *}$ & -.06 & & & \\
\hline 6. Father's weight & .01 & .00 & -.05 & -.07 & $.19^{* * *}$ & & \\
\hline 7. Child's weight & -.06 & .02 & -.08 & -.05 & $.14^{* *}$ & $.15^{* * *}$ & - \\
\hline$M(S D)$ & $3.32(0.82)$ & $2.47(0.68)$ & $2.76(0.63)$ & $2.77(0.67)$ & & & $23.19(4.71)$ \\
\hline
\end{tabular}

physical unattractiveness and this $R^{2}$ was significant, $F(6,478)=6.39, p<.001$. As predicted, conversation orientation was negatively $(\beta=-.09, p=.043)$ associated with physical unattractiveness and conformity orientation was positively $(\beta=.11, p=.020)$ associated with physical unattractiveness. The second regression model mirrored the first, but this time had weight blame as the dependent variable. Step 1 of the model (BMI and sex) contributed significantly to the regression model, $F(4,484)=3.38, p=.018$, and accounted for $3 \%$ of the variance in weight blame. Adding the two dimensions explained an additional $2 \%$ of variation in weight blame and this $R^{2}$ was significant, $F(6,482)=3.84, p=.002$. As predicted, conformity orientation was positively $(\beta=.12$, $p=.010)$ associated with weight blame, however, conversation orientation $(\beta=-.04$, n.s.) was not predictive of weight blame.

In sum, individuals from families who are high in conversation orientation are less likely to find overweight people physically unattractive. Further, the more conforming family communication is, the more individuals are likely to find overweight or obese individuals unattractive and are more likely to find overweight or obese individuals at fault for his/her appearance. When controlling for BMI (for participants, mothers, and fathers) and sex of the participant, the additional variance accounted for in antifat attitudes was small (3\% for physical unattractiveness and $2 \%$ for weight blame). Thus, conversation- and conformity orientation were found to provide a minimal contribution to antifat attitudes.

Hypothesis 2 predicted that pluralistic families (high conversation and low conformity) would be least discriminating with regard to weight in comparison to the other family types. In order to test this hypothesis, conversation and conformity orientations were each split into groups of high and low, respectively. As recommended by Koerner and Fitzpatrick (2002b), a mean split was used to create these groups. Next, high and low groups of conversation orientation were combined with high and low groups of conformity orientation. The final variable comprised the four family types (i.e., consensual $(n=82)$, pluralistic $(n=139)$, protective $(n=143)$, and laissez-faire $(n=98))$. Because a person's own weight or that of his/her parents might influence antifat attitudes and the way weight stigma is discussed, we controlled for each participant's BMI, mother's weight and father's weight. A MANCOVA was used to examine the differences between each family type (independent variable) with regard to attitudes toward physical unattractiveness and weight blame (dependent variables). Participant's BMI and parents' weight were entered as covariates. The MANCOVA revealed a significant multivariate effect for family type, Wilks' $\lambda=.95, F(6,904)=4.19$, $p<.001, \eta^{2}=.03$. Power used to detect the effect was .98. Given the significance of the overall test, the univariate main effects were examined. Univariate analyses of variance (ANOVAs) for each dependent variable were conducted as follow up tests to the MANCOVA. Using the Bonferroni method for controlling Type I error rates for multiple comparisons, each ANOVA was tested at the .03 level. Significant univariate main effects were obtained for physical unattractiveness $F(3,456)=7.45, p<.001, \eta^{2}=.05$, power $=.99$; and weight blame, $F(3,456)=6.05$, $p<.001, \eta^{2}=.04$, power $=.96$. Post hoc analyses revealed that individuals from pluralistic families $(M=2.56, S D=0.58)$ were significantly less likely than individuals from consensual $(M=2.82, S D=0.66)$, protective $(M=2.84, S D=0.65)$, and laissez-faire $(M=2.87, S D=0.62)$ families to deem "fat" people as unattractive (see Figure 1). Uniform results were found with regard to weight blame. Individuals from pluralistic families $(M=2.58, S D=0.70)$ were significantly less likely than individuals from consensual $(M=2.89, S D=0.61)$, protective $(M=2.85, S D=0.66)$, and laissez-faire $(M=2.85, S D=0.64)$ families to as- 


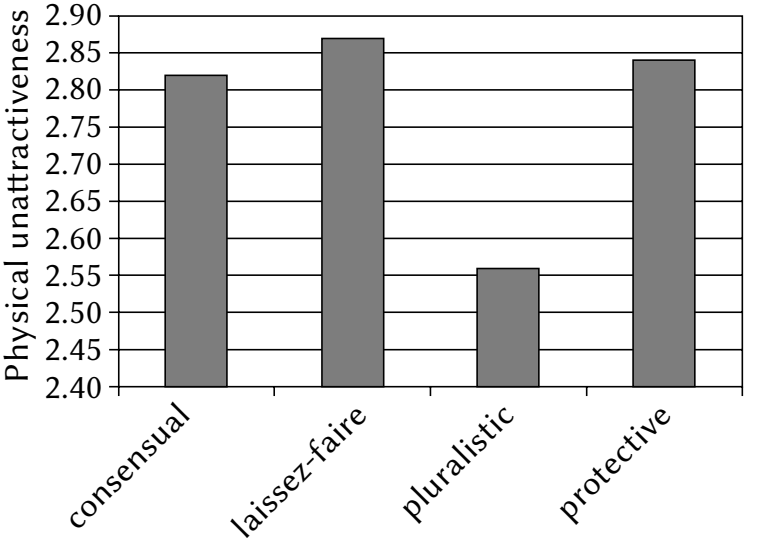

Family type

Figure 1. Means of physical unattractiveness by family type.

sign personal blame to people who are overweight or obese (see Figure 2).

Hypothesis 2 was supported as individuals from pluralistic families, compared to individuals from the other three family types (i.e., consensual, protective, and laissez-faire), held the least discriminatory attitudes toward overweight and obese people. More specifically, while controlling for one's own weight and that of his/ her mother and father, individuals who engage in family communication that is open and unrestrictive are less likely to judge a person's attractiveness based on weight and are also less likely to attach personal blame to someone for his/her weight problem.

\section{DISCUSSION}

The overarching goal of this study was to test the associations between conversation and conformity dimensions of family communication and antifat attitudes. The literature on family communication patterns (e.g., Koerner \& Fitzpatrick, 2006; Ritchie \& Fitzpatrick, 1990) has focused largely on information processing, behavioral, and psychosocial outcomes (Schrodt et al., 2008). In addition, research looking at family communication and weight focused primarily on children's behaviors (e.g., disordered eating; Arroyo \& Segrin, 2013; eating and exercise habits; Baiocchi-Wagner \& Talley, 2013; Berge et al., 2013) and body image (e.g., Al Sababah et al., 2009; Cooley et al., 2008; Kluck, 2010). At the same time, there is a void in the literature surrounding family communication and weight stigma, specifically antifat attitudes. The results of this investigation reveal that open and frequent communication (higher conversation oriented climates) is negatively associated with antifat attitudes, specifically, physical unattractiveness, whereas family communication that is restricting (higher conformity oriented climates) is positively associated with physical unattractiveness

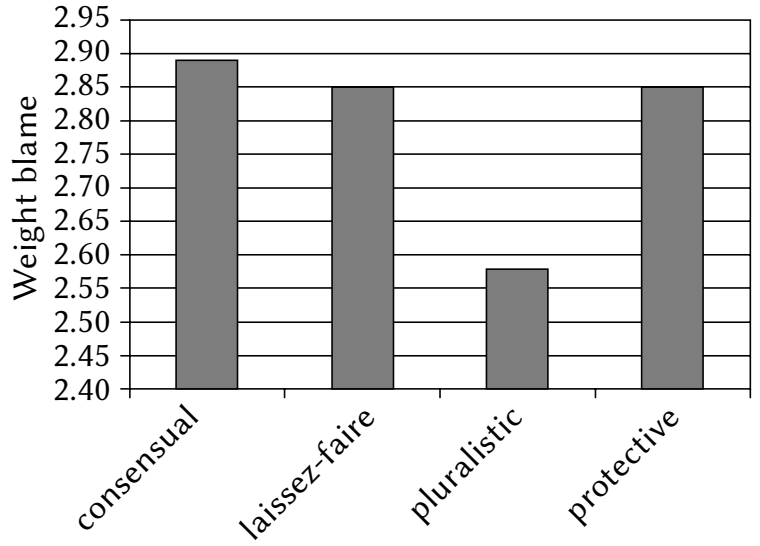

Family type

Figure 2. Means of weight blame by family type.

and weight blame. When the interaction of both dimensions was taken into consideration, results indicated that pluralistic families (high conversation and low conformity) were the least discriminatory of weight unattractivess and weight blame.

The findings of the current study confirm that family communication has a relationship to children's views of acceptable body size. Previous research has noted that weight stigma develops out of psychological variables, such as attribution (Crandall, 1994; Rush, 1998), but little research has examined the extent to which the family is associated with shaping these stigmatizing beliefs. The results of this study indicate that while there are psychological components to the development of weight stigma (see Puhl \& Brownell, 2003), family communication patterns are also associated, implying that there could also be behavioral components to the development of fat stigma. Although family communication patterns accounted for a small amount of variance in antifat attitudes, this finding should not be discounted because of its size - after all, there are undoubtedly many factors or variables that could explain antifat attitudes (e.g., peer groups, health behaviors and physical activity opportunities, health history, etc.). What remains impressive is that this finding suggests that the climate of family communication (i.e., high conversation and low conformity) could have the power to influence the development and perpetuation of weight stigma. This finding is consistent with research regarding health outcomes and family communication. The effect size indicates that this is a subject worth exploring further through future research. Research indicates that family communication can have an effect on children's eating behaviors and attitudes (Arroyo \& Segrin, 2013; Baiocchi-Wagner \& Talley, 2013; Berge et al., 2013), but this finding expands previous research in that it shows that family communication can influence children's perceptions of others' health status.
Family communication patterns and weight stigma 
The negative association between conversation orientation (i.e., the emphasis of open communication) and antifat attitudes is expected. With open communication, all family members are encouraged to talk about issues and their feelings. Based on the results of this study, we can argue that parents that emphasize communication are either doing one of two things: 1) talking about multiple causes of obesity and encouraging their children not to "judge a book by its cover" or assume the worst about an obese person; or 2) are more open and accepting of their children's body types and thus their children are also more accepting of differing body types.

Similarly, the positive relationship between conformity orientation (i.e., the emphasis placed adhering to family values and beliefs) and antifat attitudes is also not surprising, for previous research (e.g., Botta \& Dumlao, 2002; Segrin \& Flora, 2011) has shown a positive association between conformity orientation and eating disorder behaviors in children. Therefore, some families with high conformity orientation may emphasize that people should look a certain way (i.e., be thin) and those that are overweight or obese are at fault for their condition. Thus, it follows that children from these families would be more likely to judge someone more harshly based on his or her weight because they are likely to be judged about their own weight.

Consistent with Koerner and Fitzpatrick's (2002b) claim that the two dimensions consistently interact, we also found an interaction between conversation and conformity orientations with regard to weight stigma. Moreover, based on the findings of the previous variables, the negative relationship between pluralistic families and antifat attitudes was expected. Pluralistic families emphasize conversation and place little emphasis on conformity. Because these families are more accepting of other opinions and beliefs, it follows that they would also be accepting of different body types. In addition, these families would be more willing to talk about why individuals would look a certain way rather than jump to conclusions regarding weight gain. Similarly, because pluralistic families are not likely to simply accept information based on what is presented but rather encourage open discussion and are less likely to conform to certain beliefs; members of these families would be more likely to consider the notion that weight and health are different entities.

Open and frequent communication among parents and children appears to be a crucial component to children being exposed to different topics and not being afraid to ask questions about societal norms, stereotypes, and/or physical and mental stigma. After all, families high in conversation orientation believe that unrestricted communication is a necessary component to healthy family functioning and socialization (Koerner \& Fitzpatrick, 2002b). However, as suggested from this study, it is not only the pres- ence of higher conversation orientation; but rather its operation in conjunction with a lower conformity orientation. This combination of conversation and conformity orientations appears to be an important key to families being less discriminatory toward others who are overweight or obese. This finding is consistent with previous research regarding family communication and health outcomes. Previous studies (e.g., Baiocchi-Wagner \& Talley, 2013; Botta \& Dumlao, 2002) have noted that families that exhibit pluralistic traits promote positive health outcomes.

In a society where obesity is an established and growing problem (Ogden, Carroll, Kit, \& Flegal, 2012), this research has implications for the success of personal and work relationships, perpetuating stereotypes, and increasing weight stigma and discrimination. For example, family environments that allow family members to discuss multiple topics and promote personal growth could also by proxy allow for more acceptance of others and open-mindedness. Therefore, this research suggests that pluralistic family types use communication in ways that are not only less discriminating of others in comparison to other family types, but bring about more awareness and information to family members about various issues.

\section{LIMITATIONS AND FUTURE RESEARCH}

The first limitation of this research is that it is based on only one family member's perception of his/her family. Because the family is a system, it would be beneficial to obtain data from multiple family members so as to more comprehensively assess the relationships between family communication and weight. Therefore, future research surrounding weight stigma and weight talk should include the parent's perceptions at the very minimum, in addition to other sibling's perceptions. This will allow for more accuracy when assessing conversation and conformity orientations. Further, it will allow for the detection of similar attitudes and beliefs toward overweight and obese individuals among family members. Additionally, the current research was cross-sectional and the results are correlational. Therefore, we are unable to make causal statements about the order of the variables examined in this study. Although it seems likely that a person's family environment and communication processes lead to their thoughts and beliefs about obesity, it is also possible that antifat attitudes are the driving force behind family communication processes.

\section{CONCLUSIONS}

The current study emphasizes the relationship between family communication patterns and weight 
stigma. Families who adopt a high conversation orientation and low conformity orientation appear to engage in the least amount of discrimination with regard to weight stigma. The findings illustrate the importance of fostering a family environment where family members teach, listen, encourage questions and active participation from all members.

\section{RefERENCES}

Al Sabbah, H., Vereecken, C. A., Elgar, F. J., Nansel, T., Aasvee, K., Abdeen, Z., Ojala, K., Ahluwalia, N., \& Maes, L. (2009). Body weight dissatisfaction and communication with parents among adolescents in 24 countries: International cross-sectional survey. BMC Public Health, 9, 52-62. doi: 10.1186/1471-2458-9-52

Anderson, J. (2013). Communicating stigma about body size. Health Communication, 28, 603-615. doi: 10.1080/10410236.2012.706792

Andreyeva, T., Puhl, R. M., \& Brownell, K. D. (2008). Changes in perceived weight discrimination among Americans: 1995-1996 through 2004-2006. Obesity, 16, 1129-1134. doi: 10.1038/oby.2008.35

Arroyo, A., \& Segrin, C. (2013). Family interactions and disordered eating attitudes: The mediating roles of social competence and psychological distress. Communication Monographs, 80, 399-424. doi: 10.1080/03637751.2013.828158

Baiocchi-Wagner, E. A., \& Talley, A. E. (2013). The role of family communication in individual health attitudes and behaviors concerning diet and physical activity. Health Communication, 28, 193-205. doi: 10.1080/10410236.2012.674911

Berge, J. M., Wall, M., Larson, N., Loth, K. A., \& Nuemark-Sztainer, D. (2013). Family functioning: Associations with weight status, eating behaviors, and physical activity in adolescents. Journal of Adolescent Health, 53, 351-357. doi: 10.1016/j. jadohealth.2012.07.006

Botta, R. A., \& Dumlao, R. (2002). How do conflict and communication patterns between fathers and daughters contribute to or offset eating disorders? Health Communication, 14, 199-219. doi: 10.1207/ S15327027HC1402_3

Centers for Disease Control and Prevention. (2015). About adult BMI. Retrieved January 27, 2016 from http://www.cdc.gov/healthyweight/assessing/ bmi/adult_bmi/index.html

Crandall, C. S. (1994). Prejudice against fat people: Ideology and self-interest. Journal of Personality and Social Psychology, 66, 882-894. doi: 10.1037/0022-3514.66.5.882

Crandall, C. S., \& Moriarty, D. (1995). Physical illness stigma and social rejection. British Journal of Social Psychology, 34, 67-83. doi: 10.1111/j.20448309.1995.tb01049.x
Cooley, E., Toray, T., Wang, M. C., \& Valdez, N. N. (2008). Maternal effects on daughters' eating pathology and body image. Eating Behaviors, 9, 5261. doi: 10.1016/j.eatbeh.2007.03.001

Coomber, K., \& King, R. M. (2008). The role of sisters in body image dissatisfaction and disordered eating. Sex Roles, 59, 81-93. doi: 10.1007/s11199-0089413-7

Dhurandhar, N. V. (2013). Obesity stigma: A persistent problem, a possible solution. International Journal of Obesity, 37, 1413-1414. doi: 10.1038/ ijo.2013.34

Ebneter, D. S., Latner, J. D., \& O’Brien, K. S. (2011). Just world beliefs, casual beliefs, and acquaintance: Associations with stigma toward eating disorders and obesity. Personality and Individual Differences, 51, 618-622. doi: 10.1016/j.paid.2011.05.029

Elwood, T. D., \& Schrader, D. C. (1988). Family communication patterns and communication apprehension. Journal of Social Behavior and Personality, 13, 493-502.

Fitzpatrick, M. A., \& Ritchie, L. D. (1994). Communication schemata within the family: Multiple perspectives on family interaction. Human Communication Research, 20, 159-172. doi: 10.1111/ j.1468-2958.1994.tb00324.x

Goffman, E. (1963). Stigma: Notes on the management of spoiled identity. Englewood Cliffs, NJ: Prentice-Hall.

Gorber, S. C., Tremblay, M., Moher, D., \& Gorber, B. (2007). A comparison of direct vs. self-report measures for assessing height, weight and body mass index: A systematic review. Obesity Reviews, 8, 307-326. doi: 10.1111/j.1467-789X.2007.00347.x

Hansson, L. M., \& Rasmussen, F. (2014). Attitudes towards obesity in the Swedish general population: The role of one's own body size, weight satisfaction, and controllability beliefs about obesity. Body Image, 11, 43-50. doi: 10.1016/j.bodyim.2013.10.004

Hinshaw, S. P. (2007). The mark of shame: Stigma of mental illness and an agenda for change. New York: Oxford University Press.

Hinshaw, S. P., \& Stier, A. (2007). Stigma as related to mental disorders. Annual Review of Clinical Psychology, 4, 367-393. doi: 10.1146/annurev.clinpsy.4.022007.141245

Joiner, T. E., Heatherton, T. E., Rudd, M. D., \& Schmidt, N. B. (1997). Perfectionism, perceived weight status, and bulimic symptoms: Two studies testing a diathesis-stress model. Journal of Abnormal Psychology, 106, 145-153. doi: 10.1037/0021-843X.106.1.145

Katz, D. (2014). Health: The medicalization of fat. $\mathrm{Na}-$ ture, 510, 34. doi: 10.1038/510034a

Kluck, A. S. (2010). Family influence on disordered eating: The role of body image dissatisfaction. Body Image, 7, 8-14. doi: 10.1016/j.bodyim.2009.09.009
Family communication patterns and weight stigma 
Koerner, A. F., \& Fitzpatrick, M. A. (1997). Family type and conflict: The impact of conversation orientation and conformity orientation on conflict in the family. Communication Studies, 48, 59-75. doi: 10.1080/10510979709368491

Koerner, A. F. \& Fitzpatrick, M. A. (2002a). Toward a theory of family communication. Communication Theory, 12, 70-91. doi: 10.1111/j.1468-2885.2002. tb00260.x

Koerner, A. F. \& Fitzpatrick, M. A. (2002b). Understand-
Mary Beth Asbury, Alesia Woszidlo ing family communication patterns and family functioning: The roles of conversation orientation and conformity orientation. Communication Yearbook, 26, 36-68. doi: 10.1207/s15567419cy2601_2

Koerner, A. F., \& Fitzpatrick, M. A. (2006). Family communication patterns theory: A social cognitive approach. In D. O. Braithwaite \& L. A. Baxter (eds.), Engaging theories in family communication (pp. 50-65). Thousand Oaks, CA: Sage. doi: 10.4135/9781452204420.n4

Koerner, A. F., \& Schrodt, P. (2014). An introduction to the special issue on family communication patterns theory. Journal of Family Communication, 14, 1-15. doi: 10.1207/S15327698JFC0202_01

Latner, J. D., O’Brien, K. S., Durso, L. E., Brinkman, L. A., \& MacDonald, T. (2008). Weighing obesity stigma: The relative strength of different forms of bias. International Journal of Obesity, 32, 1145-1152. doi: 10.1038/ijo.2008.53

Latner, J. D., \& Stunkard, A. J. (2003). Getting worse: The stigmatization of obese children. Obesity Research, 11, 452-456. doi: 10.1038/oby.2003.61

Levine, P. (1996). Eating disorders and their impact on family systems. In F. W. Kaslow (ed.), Handbook of relational diagnosis and dysfunctional family patterns (pp. 463-476). New York: Wiley.

Lewis, R. J., Cash, T. F., Jacobi, L., \& Bubb-Lewis, C. (1997). Prejudice toward fat people: The development and validation of the anti-fat attitudes test. Obesity Research, 11, 452-456. doi: 10.1002/j.15508528.1997.tb00555.x

Mond, J. M., Robertson-Smith, G., \& Vetere, A. (2006). Stigma and eating disorders: Is there evidence of negative attitudes towards anorexia nervosa among women in the community? Journal of Mental Health, 15, 519-532. doi: 10.1080/09638230600902559

Musher-Eizenman, D. R., Holub, S. C., Miller, A. B., Goldstein, S. E., \& Edwards-Leeper, L. (2004). Body size stigmatization in preschool children. Journal of Pediatric Psychology, 29, 613-620. doi: 10.1093/jpepsy/jsh063

O'Brien, K. S., Danielsdottir, S., Olafsson, R. P., Hansdottir, I., Fridjonsdotti, T., G., \& Jonsdottiir, H. (2013). The relationship between physical appearance concerns, disgust, and anti-fat prejudice. Body Image, 10, 619-623. doi: 10.1016/j.bodyim.2013.07.012

Ogden, C. L., Carroll, M. D., Kit, B. K., \& Flegal, K. M. (2012). Prevalence of obesity in the United States,
2009-2010. NCHS data brief, no 82. Hyattsville, MD: National Center for Health Statistics.

Puhl, R. M., \& Brownell, K. D. (2001). Bias, discrimination, and obesity. Obesity Research, 9, 788-905. doi: 10.1038/oby.2001.108

Puhl, R. M., \& Brownell, K. D. (2003). Psychosocial origins of obesity stigma: Toward changing a powerful and pervasive bias. Obesity Reviews, 4, 213-227. doi: 10.1046/j.1467-789X.2003.00122.x

Puhl, R. M., \& Brownell, K. D. (2006). Confronting and coping with weight stigma: An investigation of overweight and obese adults. Obesity, 14, 18021815. doi: $10.1038 /$ oby. 2006.208

Puhl, R. M., \& Heuer, C. A. (2009). The stigma of obesity: A review and update. Obesity, 17, 941-964. doi: 10.1038/oby.2008.636

Puhl, R. M., Moss-Racusin, C. A., Schwartz, M. B., \& Brownell, K. D. (2008). Weight stigmatization and bias reduction: perspectives of overweight and obese adults. Health Education Research, 23, 347-358. doi: 10.1093/her/cym052

Roehrig, J. P., \& McLean, C. P. (2010). A comparison of stigma toward eating disorders versus depression. International Journal of Eating Disorders, 43, 671-674. doi: 10.1002/eat.20760

Ritchie, L. D., \& Fitzpatrick, M. A. (1990). Family communication patterns: Measuring intrapersonal perceptions of interpersonal relationships. Communication Research, 17, 523-544. doi: 10.1177/009365090017004007

Rush, L. L. (1998). Affective reactions to multiple social stigmas. Journal of Social Psychology, 138, 421-430. doi: 10.1080/00224549809600397

Schrodt, P., \& Ledbetter, A. M. (2007). Communication processes that mediate family communication patterns and mental well-being: A mean and covariance structures analysis of young adults from divorced and non-divorced families. $\mathrm{Hu}$ man Communication Research, 33, 330-356. doi: 10.1111/j.1468-2958.2007.00302.x

Schrodt, P., Ledbetter, A. M., \& Ohrt, J. K. (2007). Parental confirmation and affection as mediators of family communication patterns and children's mental well-being. Journal of Family Communication, 7, 23-46. doi: 10.1080/15267430709336667

Schrodt, P., Witt, P. L., \& Messersmith, A. S. (2008). A meta-analytical review of family communication patterns and their association with information processing, behavioral, and psychosocial outcomes. Communication Monographs, 75, 248-269. doi: 10.1080/03637750802256318

Segrin, C. (2006). Family interactions and well-being: Integrative perspectives. Journal of Family Communication, 6, 3-21. doi: 10.1207/s15327698jfc0601_2

Segrin, C., \& Flora, J. (2011). Family communication $\left(2^{\text {nd }}\right.$ ed.). New York, NY: Routledge.

Smith, R. A. (2007). Language of the lost: An explication of stigma communication. Communi- 
cation Theory, 17, 462-485. doi: 10.1111/j.14682885.2007.00307.x

Sutin, A. R., Stephan, Y., Carretta, H., \& Terracciano, A. (2015). Percieved discrimination and physica, cognitive, and emotional health in older adulthood. American Journal of Geriatric Psychiatry, 23, 171179. doi: 10.1016/j.jagp.2014.03.007

Taniguchi, E., \& Aune, R. K. (2013). Communication with parents and body satisfaction in college students. Journal of American College Health, 61, 387-396. doi: 10.1080/07448481.2013.820189

Tomiyama, A. J., Finch, L. E., Belsky, A. C. I., Buss, J., Finley, C., Schwartz, M. B., \& Daubenmier, J. (2015). Weight bias in 2001 versus 2013: Contradictory attitudes among obesity researchers and health professionals. Obesity, 23, 46-53. doi: 10.1002/ oby. 20910

Townsend, L. (2009). The moralizing of obesity: A new name for an old sin? Critical Social Policy, 29, 171-190. doi: 10.1177/0261018308101625

Wonderlich, S. (1992). Relationship of family and personality factors in bulimia. In J. H. Crowther, D. L. Tennenbaum, S. E. Hobfoll, \& M. A. P. Stephens (eds.), The etiology of bulimia nervosa: The individual and familial context (pp. 103-126). Washington, DC: Hemisphere. 